\title{
GCU
}

Glasgow Caledonian

University

University for the Common Good

\section{Can human evolution help us understand support for populist movements?}

Ianosev, Bogdan; Sahin, Osman

Published in:

Political Insight

DOI:

$10.1177 / 2041905820958820$

Publication date:

2020

Document Version

Author accepted manuscript

Link to publication in ResearchOnline

Citation for published version (Harvard):

lanosev, B \& Sahin, O 2020, 'Can human evolution help us understand support for populist movements?', Political Insight, vol. 11, no. 3, pp. 26-29. https://doi.org/10.1177/2041905820958820

\section{General rights}

Copyright and moral rights for the publications made accessible in the public portal are retained by the authors and/or other copyright owners and it is a condition of accessing publications that users recognise and abide by the legal requirements associated with these rights.

Take down policy

If you believe that this document breaches copyright please view our takedown policy at https://edshare.gcu.ac.uk/id/eprint/5179 for details of how to contact us. 


\section{Can human evolution help us understand the support for populist movements?}

One striking aspect of the coronavirus crisis was the poor response of the rightwing populist leaders to the pandemic in countries such as the US, Britain, and Brazil. Despite this fact, the continuing voter support right-wing populist leaders attract across countries with different socio-economic traits is puzzling. In this paper, we argue in favour of a cognitive anthropological view of populism scholarship. Cognitive and evolutionary anthropology shows that mental systems common to all humans shape the way we understand the world, making some ideas more plausible than others regardless of their levels of accuracy. Even though the action of 'building a wall' to keep illegal migrants away can prove ultimately unfeasible and does not address real immigration issues, due to our cognitive evolution, it makes intuitive sense as a plausible option to reducing immigration. Populist leaders exploit our cognitive intuitions by providing such intractable but oftentimes intuitively-plausible ideas in order to get elected or to promote preferred policies. Furthermore, we intuitively admire powerful individuals and tend to defer to authoritative and charismatic figures as an evolutionary strategy for acquiring valued skills and negotiating hierarchies. As a result, by committing to the intuitively-plausible policies populist leaders promote, such as 'building a wall', they give additional credence to the political beliefs that are based on our cognitive intuitions, effectively increasing their plausibility for the "common folk".

Keywords: evolution, populism, right-wing populism, cognitive anthropology, cognitive intuitions.

Democrats are proposing open borders, lower wages, and, frankly, lawless chaos. We are proposing an immigration plan that puts the jobs, wages, and safety of American workers first. (Applause.) Our proposal is pro-American, pro-immigrant, and pro-worker. It's just common sense. It will help all of our people, including millions of devoted immigrants, to achieve the American Dream.

Donald Trump, 2016

Leaving [the European Union] would mean that we would be taking back control. That those we elect as MPs would be the ones who make and decide our laws, rather than a bunch of unelected old men in Brussels who most people cannot name and who we cannot vote for or remove. Leaving the European Union would revitalise our democracy and mean that the big decisions were made by us instead of for us. [...] If we remain inside we will be swept up in a United States of Europe with open borders and which is soon to expand with the addition of more countries as full EU members.

Nigel Farage, 2016 
These are some of the prevalent themes in the populist discourse surrounding the 2016 Brexit referendum and the US presidential election campaign of the same year. This article will explore why such inflammatory and often times contradictory claims are so popular with voters, and why they are culturally widespread.

According to Freedom House, democracy is in retreat not only in new or fragile democracies but also in advanced democracies of the West. Scholars point at populism and populist leaders as the culprit for the decline of democracy in countries all around the world. The argument says that populist leaders such as Modi in India, Erdoğan in Turkey, and Trump in the USA undermine liberal democracy through their majoritarian tendencies and disregard for the institutions of liberal democracy. Indeed, populist leaders tend to bypass institutional checks and balances, enfeeble accountability structures, and seek to suppress the voice of their opponents as they allege the opponents do not belong to their imagined "homogenous and virtuous people”. These factors cause an erosion of democracy, putting populism under the radar of political science. In this context, we first need to understand why the appeal of populist leaders appears to be cross-culturally stable. There is also a need to understand how populist leaders manage to retain their support even when failing to deliver while in office.

Insights from cognitive anthropology may suggest tentative explanations to the questions that mainstream political science can address only partially. This article first addresses mainstream political science views on populism. Second, it discusses the cognitive appeal of populist rhetoric among target audiences from the perspective of human evolution, and provides an interdisciplinary link between the two. In doing so, we show why humans are predisposed to endorse populist slogans and vote for rightwing populist parties.

Mainstream political science has argued that populism is a symptom of the failures liberal democracy, that is, liberal democracy and institutions of liberal democracy have become unresponsive to the demands of the people, who in return have been 
allured by the populist leaders into believing that their voice is silenced. In the same vein, some scholars argued that the collapse of the ideologies of the left and the right, together with the diminishing appeal of the mainstream political parties, contributed to the rise of populist leaders. This approach has asserted that recent decades have witnessed a period where left and right have approached each other in terms of major economic and social policies. Left and right parties have converged to promote neoliberalism as the only economic model and cosmopolitanism as the main pillar of public life. These changes resulted in the exclusion of some major issues from the domain of politics, thereby leaving many concerned voters across the world worried about their future prospects. It is under these circumstances that populists who claim that they are different from the "corrupt elite” preceding them and that they represent the colours of the ordinary folk became stronger than ever. This approach however fails to explain how leaders such as Erdoğan in Turkey and Orbán in Hungary managed to stay in office and to further benefit from the anti-establishment rhetoric they espoused albeit becoming part of the establishment themselves. After all, Erdoğan has been in power for almost two decades while Orbán has been the PM for a decade now. Furthermore, these leaders are able to maintain their support even when they fail to deliver in the office. Just consider the poor response of populist leaders to the pandemic in the US, Brazil, and Britain, which already ended up costing thousands more lives in these countries. We doubt that their reluctant and inadequate response to the Covid-19 crisis will cost them much support within their voter base. We will return to this point in the end of the article.

Coming out of the cognitive sciences, cognitive anthropology is the discipline that focuses on cognitive universals -cognitive mechanisms that are shared by humans of all cultures as a result of our common brain architecture. Cognitive universals highlight the common ideas that are expressed to some extent differently in every culture and as such, cognitive anthropology could help shed light on the question of why right-wing populism is so popular cross-culturally.

Research on cognitive universals helps us to understand the emergence of widespread cultural ideas in different and unrelated regions of the ancient world. For instance, the "golden rule" of large-scale religions, prescribing to treat others as one would want 
others to treat oneself, is a core idea present in all large-scale religions, yet expressed in slightly different ways. According to evolutionary anthropologists, the golden rule is made possible by our intuitive sense of fairness. The sense of fairness is a cognitive universal that drives the intuition that one's reward from a cooperative venture should mirror one's contribution inside that venture. It also informs the morality of harm, as many studies found that, most often a harmful act is only considered immoral inasmuch as it is also considered unfair. This is why institutionalized punishment, however harmful, is most of the time not considered immoral. To this end, a cultural idea (such as the golden rule) reinforcing our intuition of fairness is likely to be cognitively attractive and hence culturally successful. Another example is the popularity of the concept of karma, where reincarnation in a future life and the quality of that life depend on the moral acts one commits in the present life. The intuition that one will ultimately get (in a future life) what one deserves (in the present life) satisfies the outstanding expectation of the sense of fairness that a yet unpunished misdeed still requires punishment. Karma fulfills this expectation and provides cognitive closure because it fits very well with the input conditions of the sense of fairness. Accordingly, belief in karma is widespread because the sense of fairness is universal.

Surveying 60 human cultures around the world, research on cognitive universals by Oxford University anthropologists have identified seven universal areas of moral concern, which include but are not limited to fairness in collaboration and resource distribution, in-group loyalty and protection against out-groups (for an extended outline see Table 1 in the Appendix). Evolutionary scientists believe that these domains are specifically attended to by specialized human cognitive mechanisms in the form of domain-specific intuitions, 'rough-and-ready' inferences that evolved to generate rapid behavioural responses to fairness-and group-related threats and opportunities. These intuitions are not thorough assessments of a situation but rather an alarm call for possible threats. They come in the guise of "cognitive feelings" that “feel right” when triggered, because our brains confer them heightened relevancy. Importantly, although generating stable and meaningful responses to various types of stimuli in most areas of concern, our intuitions may at times fail to properly account for the intricacies of modern day macroeconomics, trade, or international relations. This is because they have evolved in a time when all human experience was confined to small-scale hunter-gatherer tribes, when there were limited resources available, 
zero-sum trade patterns applied, and when there was a fair chance that other tribes were posing a realistic threat to the in-group. So, how can our intuitive responses be triggered by right-wing populist discourse?

In the campaign ahead of the 2016 Brexit referendum, the winning side (i.e., Vote Leave) deployed slogans explicitly directed at our evolved intuitions, triggering rapid responses in their audience, and managing to successfully circumvent any attempt at reasonable debate. Sound-bites such as "take back control”, “immigrants taking our jobs", "immigrants putting a strain on the NHS", or " $£ 350$ million for the NHS" triggered those intuitions governing domains of fairness in collaboration and resource distribution as well as inter-group competition. Right-wing populists in Britain have put forward the idea that the EU is treating the UK unfairly; that it dominates Britain, and that it disables the UK's ability to legislate on its own. These slogans directly address intuitions that resources available to the in-group are finite and that others may take them away from "us”. For instance, rewiring $£ 350$ million to the NHS as a slogan, otherwise a price of EU membership, may make intuitive sense, but is not technically accurate, and even untrue. However, it makes sense because this simple claim activates both our intuitions of folk physics (about rough amounts and interchangeable quantities) and folk economics (about the zero-sum nature of limited resource distribution). The same intuitions also work to promote inter-group competition attitudes when portraying other countries or supranational institutions such as China or the EU, in adversarial terms. According to our coalitional intuitions that portray inter-group relations in terms of zero-sum competition, a gain for the outgroup equals a loss for the in-group. China gaining on trade can trigger the belief that there is a "trade war" going on in which the US is losing out.

This points to another important feature of intuitions, namely that they may be fast and attention grabbing, but they are not always correct. This is mostly a result of the mismatch between our ancient intuitions and present day politics. Because our intuitions are rapid and domain-specific, they do not really communicate with one another. Instead, they only provide independent “assessments” or best guesses, each addressing a particular kind of stimuli. This was reflected in the statements of early pro-Brexit politicians who promised "closed borders "and "controlled immigration", at the same time with "frictionless trade”. Although this idea is intuitively plausible, it 
is also contradictory. Such shortcomings and contradictions are the side effects of a mind designed to respond quickly and adaptively to its environment, which eventually works to the advantage of the populist leaders who often make such contradictory statements.

Another reason why often-charismatic, right-wing populist leaders manage to maintain their support has to do with their ability to appeal to voters by capitalizing on such intuitively-informed worldviews and by conferring credibility to the oftentimes simplistic, identity-based narratives that sustain them. Converging evidence from primatology - a branch of science focusing on primates - and cognitive and evolutionary anthropology have shown that humans and great apes exhibit similar patterns of attraction towards dominant individuals. Moreover, in both humans and great apes, lower-ranking individuals rely on alliances with higherranking individuals to successfully negotiate their position in social hierarchies. In addition, humans are attracted by the prestige of dominant individuals. They tend to behave pro-socially towards such individuals, defer to their knowledge and grant them more influence in collective decision-making. Hence, resulting from our natural predisposition of being attracted to, of admiring, and of imitating those with power and prestige, we give heightened credence to the words authoritative and charismatic figures utter, as they enforce our beliefs by banking on our intuitions.

So, how does research on human cognition help us to understand right-wing populists' ability to maintain their support within their voter base despite their poor performance in the office? Research findings have repeatedly uncovered associations between various types of epistemically unwarranted beliefs, such as paranormal beliefs, beliefs in conspiracy theories and pseudoscience, while research in political studies has also highlighted common traits underlying some unwarranted beliefs like conspiracism and right-wing populism. What all unwarranted beliefs seem to have in common is a higher reliance on intuitive thinking, which has its downside. For instance, our intuitive cognition is ill equipped to properly grasp statistical probabilities such as those involved in getting cancer by smoking, in understanding human-caused climate change, or in understanding epidemiological spread. In all three cases the threats are invisible (e.g., Covid-19), and their causes and mechanisms are not readily perceptible, whereas salient counter examples (e.g., "I don't wear a 
mask and I don’t get sick” or “My grandmother smoked her entire life and managed to avoid cancer”), being much more intuitive and straightforward, can mislead us into wrongfully dismissing a real threat. As a result, a higher reliance on intuitions, characteristic of conspiratorial and right-wing populist views, is more likely to focus on simple explanations and salient anecdotes to the detriment of scientific analysis or medical expertise.

During the peak of the pandemic in the US, individuals affiliated with the re-election campaign of US president Donald Trump, conservative activists and pro-gun-right groups have organized and promoted anti-lockdown protests, specifically targeting and opposing Democrat governors' efforts to keep a lockdown, in place in accordance with health recommendations. Protestors believed that the restrictions imposed by Democrat governors were too harsh, even tyrannical. In the UK, Trump voters and conspiracy minded Britons operationalized the Covid-19 pandemic under the name "Plandemic", referencing the title of a conspiracy theory video, which promotes misinformation about the pandemic. Both conspiracy theories and right-wing populism are underscored by the belief that mainstream media and establishment politicians are malevolent actors in an evil conspiracy striving to dominate and subdue ordinary people, taking away their freedoms. Moreover, both right-wing populists and conspiracy theorists tend to explain important world events as outcomes of the actions of (hidden) powerful agents, a feature present in other highly intuitive worldviews such as religion. This is also the reason why a populist leader such as Trump, who has no respect for expert opinion and who propagates the view that China is behind the pandemic, remains attractive for his supporters. His management of the pandemic is in line with the conspiracism of the voters.

If cognitive universals are the reason behind increasing and continuing electoral support for right-wing populist leaders, why has electoral support for populist leaders dramatically increased only in recent decades in the world? A major reason is available communication technologies. The technological peculiarities of our times afford populist leaders considerable leeway to circumvent traditional media outlets and to reach voters directly. Active populist politicians such as Donald Trump, Narendra Modi and Recep Tayyip Erdoğan have the highest number of followers on Twitter, allowing these leaders to bypass any kind of mediation while communicating 
their message. In this respect, it should come as no surprise that populist leaders such as Trump use social media more effectively than many mainstream politicians. Social media messaging is generally impervious to fact-checking mechanisms of any kind. This is an advantage for right-wing populists who rely on references to vaguely constructed notions of the imagined community, or the "heartland", and of scaremongering.

The second major reason is the increasing uncertainties that people face in the world. The collapse of the Soviet bloc did not bring about an uninterrupted economic growth as promised. On the contrary, neoliberal economic policies, which became popular in the post-Cold War era, caused a deterioration of employment conditions as well as a reduced access to the welfare state in the world. In this new era, neoliberal economic policies affect all societies, and ordinary citizens face more and more uncertainties in their daily lives. This new economic context strengthens the feeling that resources are finite and up for grabs by alien factors - migrants, or the 'corrupt elite'. By repeatedly 'fabricating threats' fit for our evolved intuitions, populist actors receive peoples' support despite their failure to alleviate the problems of their voters while in office.

Being led as much by forces of evolution as we are by our own free will can sound strange. However cognitive anthropology presents strong evidence in favour of this proposition. We therefore believe that this newly emerging discipline has strong potential to contribute to our efforts of understanding human societies and their politics. 


\section{Appendix.}

The following table contains a list of seven universal moral concerns accompanied by some of their attributes as identified by Curry, Mullins, and Whitehouse (2019), as well as a few proposed cognitive universals and processes likely driving their salience cross-culturally.

\begin{tabular}{|c|c|c|c|}
\hline 1. Family & $\begin{array}{l}\text { Helping family } \\
\text { members }\end{array}$ & $\begin{array}{l}\text { Helping, favouring, } \\
\text { loving, giving } \\
\text { preferential } \\
\text { treatment to, and } \\
\text { siding with kin }\end{array}$ & $\begin{array}{l}\text { kin selection } \\
\text { intuitions, incest } \\
\text { avoidance intuitions }\end{array}$ \\
\hline 2. Group & $\begin{array}{l}\text { Helping group } \\
\text { members }\end{array}$ & $\begin{array}{l}\text { Forming alliances } \\
\text { and friendships, } \\
\text { adopting local norms, } \\
\text { siding with your } \\
\text { group, giving } \\
\text { preferential } \\
\text { treatment to } \\
\text { members of your } \\
\text { group, fighting for } \\
\text { your group }\end{array}$ & $\begin{array}{l}\text { coalitional } \\
\text { psychology, zero-sum } \\
\text { intuitions, } \\
\text { ingroup/loyalty moral } \\
\text { intuitions, intuition of } \\
\text { exclusive group } \\
\text { membership, extended } \\
\text { kin selection }\end{array}$ \\
\hline 3. Reciprocity & $\begin{array}{l}\text { Engaging in } \\
\text { reciprocal } \\
\text { cooperation }\end{array}$ & $\begin{array}{l}\text { Engaging Returning a } \\
\text { favour, paying a debt, } \\
\text { fulfilling a contract, } \\
\text { seeking } \\
\text { compensation or } \\
\text { revenge, making } \\
\text { amends for cheating }\end{array}$ & $\begin{array}{l}\text { sense of fairness, } \\
\text { cheater-detection } \\
\text { system, deservingness } \\
\text { heuristic }\end{array}$ \\
\hline 4. Bravery & Being brave & $\begin{array}{l}\text { Being courageous in } \\
\text { battle, putting } \\
\text { yourself at risk to }\end{array}$ & $\begin{array}{l}\text { reputation } \\
\text { management and } \\
\text { altruism intuitions, }\end{array}$ \\
\hline
\end{tabular}




\begin{tabular}{|c|c|c|c|}
\hline & & help others & $\begin{array}{l}\text { coalitional } \\
\text { psychology, credibility } \\
\text { enhancing displays, } \\
\text { costly signalling }\end{array}$ \\
\hline 5. Respect & $\begin{array}{l}\text { Respecting your } \\
\text { superiors }\end{array}$ & $\begin{array}{l}\text { Being deferential, } \\
\text { respectful, and loyal } \\
\text { to those above you in } \\
\text { the social hierarchy }\end{array}$ & $\begin{array}{l}\text { prestige bias, } \\
\text { ingroup/loyalty moral } \\
\text { intuitions, credibility } \\
\text { enhancing displays }\end{array}$ \\
\hline 6. $\quad$ Fairness & $\begin{array}{l}\text { Dividing a disputed } \\
\text { resource }\end{array}$ & $\begin{array}{l}\text { Dividing foraging } \\
\text { spoils equitably, } \\
\text { compromising }\end{array}$ & sense of fairness \\
\hline 7. Property & $\begin{array}{l}\text { Respecting other's } \\
\text { property }\end{array}$ & $\begin{array}{l}\text { Respecting others } \\
\text { property and } \\
\text { territory: no stealing, } \\
\text { no using without } \\
\text { permission, no } \\
\text { trespassing }\end{array}$ & $\begin{array}{l}\text { universal property } \\
\text { intuitions (e.g., } \\
\text { previous possession, } \\
\text { manufactured items, } \\
\text { extracted or } \\
\text { processed natural } \\
\text { resources), sense of } \\
\text { fairness }\end{array}$ \\
\hline
\end{tabular}




\section{Suggested readings}

Baumard, N. \& Boyer, P., (2013) Explaining Moral Religions, Trends in Cognitive Sciences, 17 (6) pp. $172-180$.

Baumard, N. \& Chevallier, C. (2012) What goes around comes around: The evolutionary roots of the belief in immanent justice, Journal of Cognition and Culture.

Bergmann, E. (2018) Conspiracy \& populism: The politics of misinformation. Palgrave Macmillan, Switzerland.

Boyer, P. and Petersen M. B. (2018) Folk-economic beliefs: An evolutionary cognitive model. Behavioral and Brain Sciences, doi: 10.1017/S0140525X17001960, pp. 1-65.

Curry, O. S.; Mullins, D. A. and Whitehouse, H. (2019) Is It Good to Cooperate? Testing the Theory of Morality-as-Cooperation in 60 Societies. Current Anthropology, Vol. 60, No. 1, pp. 47-69.

Kaltwasser, C. R.; Taggart, P.A.; Espejo, P.O. and Ostiguy, P. (2017) The Oxford Handbook of Populism. OUP Oxford.

Sperber, D. (1985) Anthropology and Psychology: Towards an Epidemiology of Representations. Man, New Series, Vol. 20, No. 1, pp. 73-89. 